\title{
Effect of Temperature on Some Nano free Volume Parameters in Natural Rubber
}

\author{
M. Mohsen ${ }^{a}$, M.S. Abd El Keriem ${ }^{a}$, M. Sharaf ${ }^{b}$ and A. Amer $^{a}$ \\ Email: magdy36721@yahoo.com
}

\author{
${ }^{a}$ Physics Department, Faculty of Science, Ain Shams University, 11566, \\ Abbassia, ,Cairo, Egypt \\ ${ }^{b}$ Chemistry Department, Faculty of Science, Helwan University, \\ Cairo, Egypt
}

Positron annihilation lifetime (PAL) technique is applied on natural rubber to determine the parameters of nano free volumes such as size, concentration and distribution as a function of temperature. In agreement with the Differential Scanning Calorimeter (DSC) measurements and X-ray diffraction (XRD) measurements, the results showed that the (PAL) technique is sensitive to probe the glass transition temperature $\left(T_{g}\right)$ and its ability to determine the melting transition temperature $\left(T_{m}\right)$. Above $T_{g}$, the isothermal measurements showed an intermediate transition point before the melting point. Moreover, the ortho-positronium (o-Ps) was able to probe the variation of free volumes in the amorphous domains with the change of temperature. The calculated expansion coefficient of free volume indicates that o-Ps is selectively probing free volume sites in amorphous domains.

\section{Introduction}

Polymers have become an increasingly important group of engineering materials. Some important industries such as those for fibers, rubbers and plastics are based on polymers. Utilization of polymers in industrial applications requires a basic understanding of their physical properties. One of the important properties of polymeric materials is their mechanical flexibility in engineering processing; where the existence of free volumes in polymers plays an important role. Therefore, applying positron annihilation lifetime spectroscopy (PALS) is essential for studying polymeric material such as natural rubber.

A correlation between ortho-positronium (o-Ps) lifetime components and the Young's modulus in butyl rubber filled with carbon black was reported [1]. The effect of temperature on the lifetime component $\tau_{3}$ and its concentration $\mathrm{I}_{3}$ in polyisoprene samples for the temperature range from 150 to $300 \mathrm{~K}$ was 
measured; a minimum in $I_{3}$ just above the glass transition temperature $\left(T_{g}\right)$ was also observed [2]. The positron annihilation lifetime (PAL) as a probe for free volumes in three natural polyisoprene samples with different percentages of dicumyl peroxide additives and one synthetic isoprene sample as a function of temperature $\left(-196^{\circ} \mathrm{C}\right.$ to $\left.42^{\circ} \mathrm{C}\right)$ was used [3]. PAL was applied to investigate microstructure properties of carbon black- silica- styrene butadiene rubber (SBR) composites [4]. Nuclear magnetic resonance (NMR) was carried out to examine crystallinity, chain mobility in real time during crystallization of $\mathrm{cis}_{1,4}$ polyisoprene samples [5]. Positron annihilation lifetime spectroscopy was used to estimate the size and number density of free volume sites in copolymer of styrene and butadiene rubber [6]. PALS combined with DSC was applied to characterize the nanoscale free volume in butadiene acrylonitrile copolymer (NBR) polyethylene (PE) blends [7].

The aim of this work is to study the nanoscale free volume in natural rubber using PAL technique combined with DSC and X-ray diffraction.

\section{Experiment}

\subsection{Sample: Natural Rubber}

Samples that used in the present study was coming from on tree source, Hevea rubber tree (Hevea brasiliensis) which is the only plant species being cultivated for commercial production of rubber in the world. The samples are classical flat specimen $10 \mathrm{~mm}$ in length, $5 \mathrm{~mm}$ in width and $1 \mathrm{~mm}$ thickness.

\subsection{Positron Annihilation Technique}

Positron lifetime measurements were performed for natural rubber using a conventional fast-fast coincidence spectrometer with a time resolution of 300 ps (FWHM). A positron source ${ }^{22} \mathrm{Na}$ was prepared by depositing about $20 \mu \mathrm{C}$ of $\mathrm{NaCl}$ solution on kapton foil $(7 \mu \mathrm{m}$ thick), then sandwiched between two identical measured samples. The two samples including the positron source were fixed on the cooling finger of a closed cycle Helium cryostat (air cooled compressor model 8200). The cold head (model 22) of this cooling system includes design features optimized specifically for the positron annihilation measurements. The sample was cooled indirectly, using static helium exchange gas inside the sample chamber. The temperature was controlled by a Lakeshore temperature controller (model 321), which could maintain the temperature of the samples to within $0.1 \mathrm{~K}$. The polymer sample was cooled down to the selected temperature, (ranging from $100{ }^{\circ} \mathrm{C}$ to $40{ }^{\circ} \mathrm{C}$ ) and then the positron lifetime spectrum was recorded at the given temperature. The lifetime spectra were resolved into four components using the LT 9.0 program [8], which allows both discrete and $\log$ normal distribution of annihilation rate $\lambda=1 / \tau$. The finite- 
term analysis is a method used for the determination of the mean size and fraction of free volume holes. Whereas the continuous lifetime analysis yields a distribution of the o-Ps annihilation rate $\lambda_{4}=1 / \tau_{4}$, the size distribution of free volume holes can be calculated.

In the finite-term analysis, the experimental lifetime spectrum $Y(t)$ is expressed as convolution of the instrument resolution function $R(t)$ with a finite number (n) of negative exponentials plus a background $(B)$ [9], where:

$$
\left.Y(t)=R(t) *\left(N_{t} \sum_{i=1}^{n} \alpha_{i} \lambda_{i} e^{-\lambda_{i} t}+B\right)\right)
$$

hence $N_{i}$ is the normalized total counts, $\lambda_{i}$ is the annihilation rate $\left(=1 / \tau_{\mathrm{i}}\right)$ and $\left(\lambda_{i}\right.$ $\left.\alpha_{i}\right)$ is the intensity. The fitting parameters $\lambda_{i}$ and $\alpha_{i}$ (with $\left.\mathrm{i}=1,2,3,4\right)$ were obtained using the least-square fit to the experimental lifetime spectrum $Y(t)$ in Eq. (1).

Lifetime analysis decomposed the PAL spectrum into four different states of positron annihilation; the shortest -lived component $\tau_{1}$ with intensity $\mathrm{I}_{1}$ was attributed to the annihilation of p-Ps. The intermediate components $\tau_{2}$ with intensity $I_{2}$ and $\tau_{3}$ with intensities $I_{3}$ were mainly due to the positrons trapped in the defects present in the crystalline regions and crystalline-amorphous interphase regions [10]. The longest component lifetime $\tau_{4}$ with intensity $\mathrm{I}_{4}$ was due to the pick-off annihilation of o-Ps in the amorphous region of the polymer matrix [11].

According to the model proposed by Tao [12] and Eldrup et al. [13], the o-Ps lifetime $\tau_{4}$ is related to the size of the free volume in which the o-Ps annihilates. Positronium (Ps) is assumed to be localized in a spherical potential well having an infinite potential barrier of radius $\mathrm{R}_{\mathrm{o}}\left(=\mathrm{R}_{\mathrm{h}}+\delta \mathrm{R}\right)$ with an electron layer. The average radius of the free volume holes $\left(R_{h}\right)$, can be determined from the following relation [14]:

$$
\tau_{4}=0.5\left[1-\frac{R_{h}}{R_{h}+\partial R}+\frac{1}{2 \pi R_{h}} \sin \left(\frac{2 \pi R_{h}}{R_{h}+\partial R}\right)\right]^{-1}
$$

where $\delta \mathrm{R}$ is the thickness of the electron layer. The assumption is that the lifetime of the o-Ps in the electron layer is the spin-averaged Ps lifetime of 0.5 $\mathrm{ns}[13,15] . \delta \mathrm{R}=1.66 \AA$ was determined by fitting Eq. (2) with experimental $\tau_{4}$ values of molecular materials with known hole sizes. The free volume size $V_{h}$ was calculated as $V_{h}=4 \pi R_{h}^{3} / 3$, where as the relative fractional free volume $f v=$ $\mathrm{V}_{\mathrm{h}} \mathrm{I}_{3}$. 
Since the free volume hole radii are likely to exist in a distribution, the o-Ps lifetime is expressed as a distribution rather than as discrete values. In the continuous lifetime analysis, a PAL spectrum is given in a continuous decay as:

$$
\left.Y(t)=R(t)\left(N_{t} \int_{0}^{\infty} \lambda \alpha(\lambda) e^{-\lambda t} d t+B\right)\right)
$$

The integral in parenthesis is simply a Laplace transformation of the function $\lambda \alpha(\lambda)$, where $\alpha(\lambda)$ is the probability density function of the annihilation rate $\lambda=1 / \tau[16]$.

\subsection{Differential Scanning Calorimeter (DSC)}

Differential Scanning Calorimeter (DSC) was used to measure the glass temperature $\left(\mathrm{T}_{\mathrm{g}}\right)$, the crystallization transition temperature $\left(\mathrm{T}_{\mathrm{c}}\right)$ and the melting temperature $\left(\mathrm{T}_{\mathrm{M}}\right)$. The crystalline melting point of a polymer corresponds to a change in the state from a solid to a liquid is represented as endothermic peak in a DSC curve. In addition, to determine the melting point and heat of fusion from DSC, the width of the melting range was indicative of the range of crystal size and perfection. Isothermal crystallization could occur at a range of temperatures below $\mathrm{T}_{\mathrm{M}}$ and above $\mathrm{T}_{\mathrm{g}}$.

\section{4. $\mathrm{X}$ ray diffraction}

Philips powder diffractometer of X'pert (MPD) system with BraggBrentano para focusing of reflection geometry technique and graphite monochromated Mo $\mathrm{K} \alpha$ radiation $(\lambda=0.709 \AA)$ was applied in the studied samples. A fixed divergence slit of $1^{\circ}$ and a receiving slit of a height $0.1 \mathrm{~mm}$ were used. Soller slits of $0.04 \mathrm{rad}$ was used in both the incident and diffracted beam. Data were collected over the range $0^{\circ} \leq 2 \theta \geq 90^{\circ}$ in $0.03^{\circ}$ steps with a counting time $10 \mathrm{~s}$. The collected data range gives an accessible scattering vector magnitude $(\mathrm{k})$ of about 16.0. This value provides a reasonable resolution in both the inverted space (K-space) and also the real space (R-space).

\subsection{Tensile deformation}

Deformation of the samples was obtained by using the tensile apparatus in situ with the PAL spectrometer. The positron annihilation experiment was started after the rubber sample was stretched to $(300 \%)$, then held at a constant elongation during the positron annihilation measurements. 


\section{Results and Discussion}

\subsection{Annihilation of free positrons}

Figures $1(a, b)$ and $2(a, b)$ show the variation of the second $\left(\tau_{2}, I_{2}\right)$ and third $\left(\tau_{3}, I_{3}\right)$ lifetime components verses the temperature which are associated with annihilation of free positrons in the crystal domains and interface, respectively. The lifetime components $\left(\tau_{2}\right.$ and $\left.\tau_{3}\right)$ show similar variation trend where one can observes a weak increase below $\mathrm{T}_{\mathrm{g}}\left(-70^{\circ} \mathrm{C}\right)$ and a stronger increase above $\mathrm{T}_{\mathrm{g}}$ up to $-30^{\circ} \mathrm{C}$. In addition, the two lifetimes show a weak variation till the melting temperature $\mathrm{T}_{\mathrm{M}}\left(30^{\circ} \mathrm{C}\right)$. However, the population of the crystal and interface domains, which are represented by $\left(\mathrm{I}_{2}\right.$ and $\left.\mathrm{I}_{3}\right)$ respectively, show opposite variation trends at $-30^{\circ} \mathrm{C}$ whereas $\mathrm{I}_{2}$ increases from $55 \%$ to $65 \%$ and $\mathrm{I}_{3}$ decreases from $18 \%$ to $3 \%$. This may be due to the combination of some small size defects to form new defects with bigger sizes and low fractions.

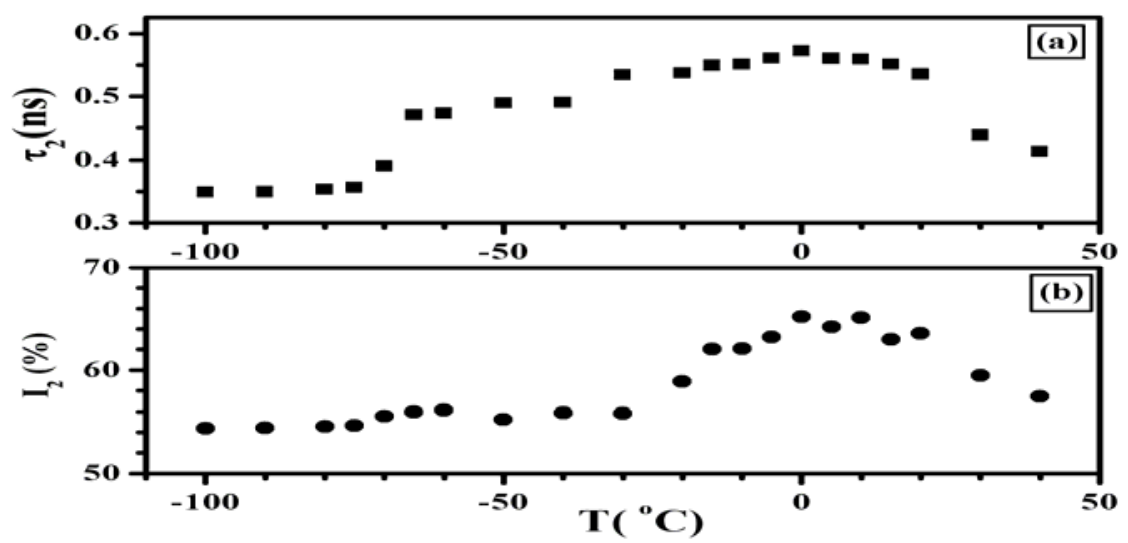

Fig. $\left(\mathbf{1}\right.$ a,b): The temperature variation of the second lifetime components, $\left(\tau_{2}, I_{2}\right)$ in natural rubber.

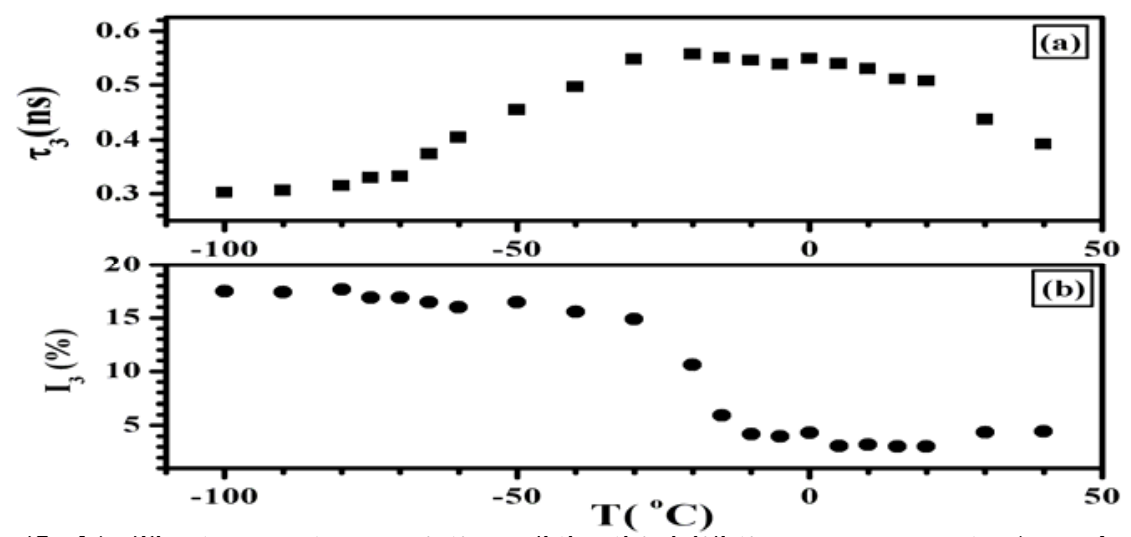

Fig. (2a,b): The temperature variation of the third lifetime components, $\left(\tau_{3}, I_{3}\right)$ in natural rubber. 


\subsection{Ortho positronium annihilation in free volumes}

Figure $3(\mathrm{a}, \mathrm{b})$ shows the temperature variation of the o-Ps lifetime components $\left(\tau_{4}, \mathrm{I}_{4}\right)$ for natural rubber versus temperature. It provides information on the microstructure changes in amorphous region of polymers [11]. The lifetime $\left(\tau_{4}\right)$ is ranging from 1.5 to $3.5 \mathrm{~ns}$ and its intensities $\left(\mathrm{I}_{4}\right)$ ranging from 18 to $28 \%$. The measurements conclude that:

(a) At low temperature $\left(\mathrm{T}<\mathrm{T}_{\mathrm{g}}\right)$, the o-Ps lifetime components $\left(\tau_{4}\right.$ and $\left.\mathrm{I}_{4}\right)$ do not vary considerably with temperature because all motions including molecules and chains at this temperature are completely froze [17].

(b) During the isothermal measurements, the temperature variation show an intermediate transition point $\left(\mathrm{T}_{\mathrm{o}}=-20 \mathrm{C}^{\circ}\right)$ above the glass temperature $\left(\mathrm{T}_{\mathrm{g}}\right)$ and before the melting temperature $\left(\mathrm{T}_{\mathrm{M}}\right)$ which can be attributed to less stable crystalline phase.

(c) The steepest change in $\tau_{4}$ and $\mathrm{I}_{4}$ with temperature occurs at $\left(\mathrm{T}_{\mathrm{g}}\right)$ and liquid transition $\left(T_{0}\right)$ temperature. This is due to the main- chain segmental motion and the increase of mobilization in polymer matrix. This can increase the free volume size in the amorphous domain and consequently increase

the o-Ps lifetime $\left(\tau_{4}\right)$ from 1.5 to $3.5 \mathrm{~ns}$ and its fractions $\left(\mathrm{I}_{4}\right)$ from 18 to $28 \%$.

(d) Above $\mathrm{T}_{\mathrm{M}}$, polymers are in a real liquid state having a relaxation time that is comparable to o-Ps lifetime. In this state, Ps creates a large new open space, called Ps-bubble, which has a size of few angstroms. Therefore $\tau_{4}$ tends to decrease and $\mathrm{I}_{4}$ to increase [18].

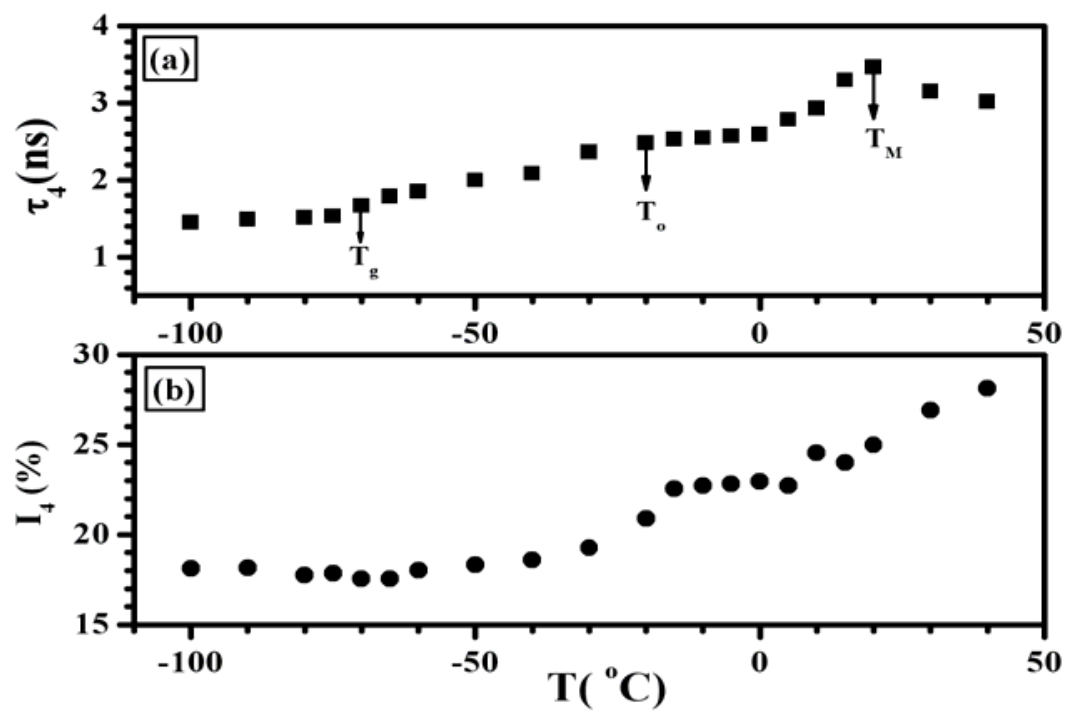

Fig. (3a,b): The temperature variation of the o-Ps lifetime components, $\left(\tau_{4}, \mathrm{I}_{4}\right)$ in natural rubber. 


\subsection{Thermal expansion coefficient:}

To analyze the transition point $\left(T_{0}\right)$, the free volume fractions $\left(f_{v}\right)$ were estimated as a function of temperature according to the following equation:

$$
\mathrm{f}_{\mathrm{v}}=0.025+\left(\mathrm{T}-\mathrm{T}_{\mathrm{g}}\right) \alpha_{\mathrm{f}} .
$$

where $\alpha_{\mathrm{f}}$ is the thermal expansion coefficient for free volume.The results are listed in Table (1).

Table (1): Comparison of free volume expansion coefficient $\alpha_{\mathrm{f}}$ and volume expansion coefficient.

\begin{tabular}{|c|c|c|c|c|}
\hline Temperature & $\mathrm{T}<\mathrm{Tg}$ & $\mathrm{T}>\mathrm{Tg}$ & $\mathrm{T}>\mathrm{T}_{\mathrm{M}}$ & $\begin{array}{c}\text { Volume expansion } \\
\text { coefficient }\end{array}$ \\
\hline$\alpha_{\mathrm{f}}$ & $5.9 \times 10^{-3} \mathrm{~K}^{-1}$ & $74 \times 10^{-3} \mathrm{~K}^{-1}$ & $25 \times 10^{-3} \mathrm{~K}^{-1}$ & $6.6 \times 10^{-4} \mathrm{~K}^{-1}$ \\
\hline
\end{tabular}

From Table (1), one can observe that: $\alpha_{\mathrm{f}}$ in free volume is about more than one order of magnitude higher than the normal thermal expansion coefficient of rubber. It indicates a strong evidence of Ps trapping in free volume sites, which exists only in the amorphous domains. Therefore, the increase of $\mathrm{I}_{4}$ from 18 to $28 \%$, Fig. (3b), can be assigned to the increase in amorphous domains with temperature. Also, Fig. (4) indicates that: Below $\mathrm{T}_{\mathrm{g}}$, all motions including molecules and chains are completely frozen [17] where $f_{v}$ is constant. Above $T_{g}$ the matrix becomes rubbery and the chain mobility increases with temperature, thus increasing the fractional free volume content. In addition, an_intermediate transition point at $\mathrm{T}_{0}=-20^{\circ} \mathrm{C}$ before the melting point could be resolved. This transition indicates the presence of a less stable crystalline phase. At the melting point $\mathrm{T}_{\mathrm{M}}=30{ }^{\circ} \mathrm{C}$, the free volume fraction $\left(\mathrm{f}_{\mathrm{v}}\right)$ reachs maximum.

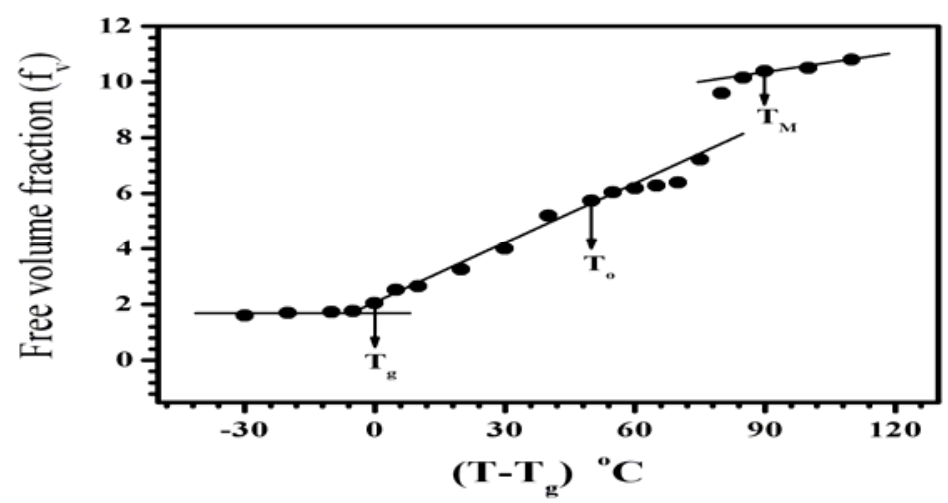

Fig. (4): The temperature variation of free volume fractions $\left(f_{v}\right)$. 


\subsection{Free volume distributions}

Figure (5) shows the variation of the free volume size distribution as a function of temperature. Below $\mathrm{T}_{\mathrm{g}}$, the free volume distribution shows an average volume of $45 \mathrm{~A}^{03}$. Where as above $\mathrm{T}_{\mathrm{g}}$, the distribution is shifted to larger free volume size $149 \mathrm{~A}^{03}$ at the transition temperature $T_{0}$ and reaching a maximum value of $252 \mathrm{~A}^{03}$ at $\mathrm{T}_{\mathrm{M}}$. The distribution size is shifted to a lower free volume size at $\mathrm{T}>\mathrm{T}_{\mathrm{M}}$, reaching $199 \mathrm{~A}^{\mathrm{o} 3}$ at $40^{\circ} \mathrm{C}$ where the polymer becomes in a real liquid state.

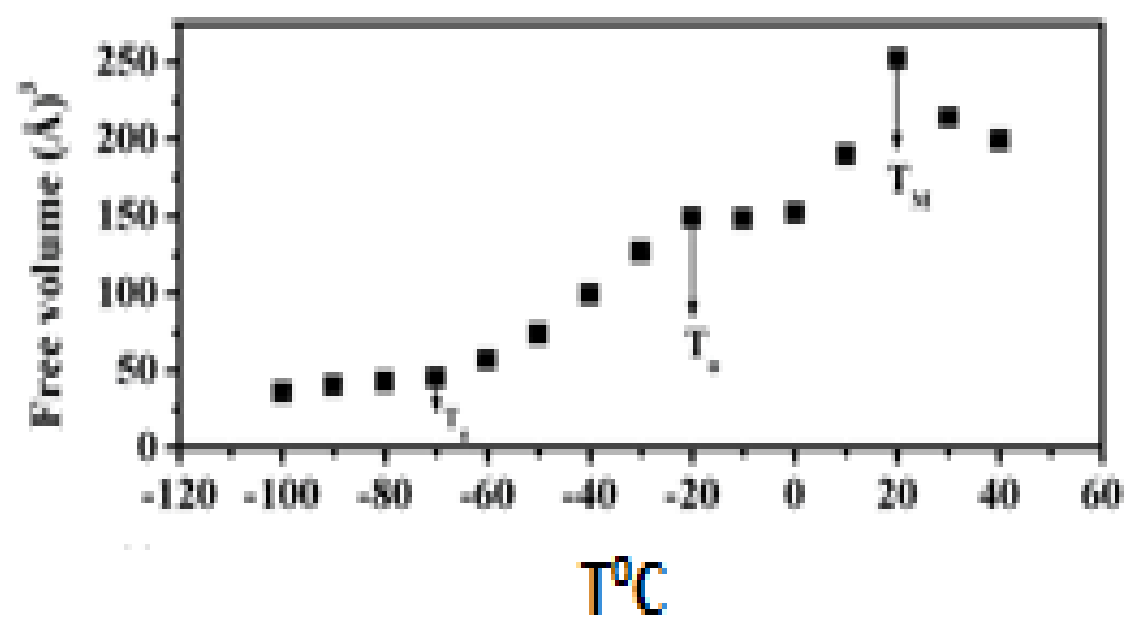

Fig. (5): Free volume hole size at different temperatures in nutural rubber.

\subsection{DSC Measurements:}

DSC was performed to characterize the $T_{g}$ and $T_{M}$ of natural rubber Fig (6). The $T_{g}$ value deduced from PAL measurements was found to be few degrees different from that obtained by DSC. This is due to the fact that, the duration of PAL measurement is (3.4) hours whereas DSC measurement is less than a minute. Thus the longer time may affect the relaxation of molecular chains and show a temperature difference. 


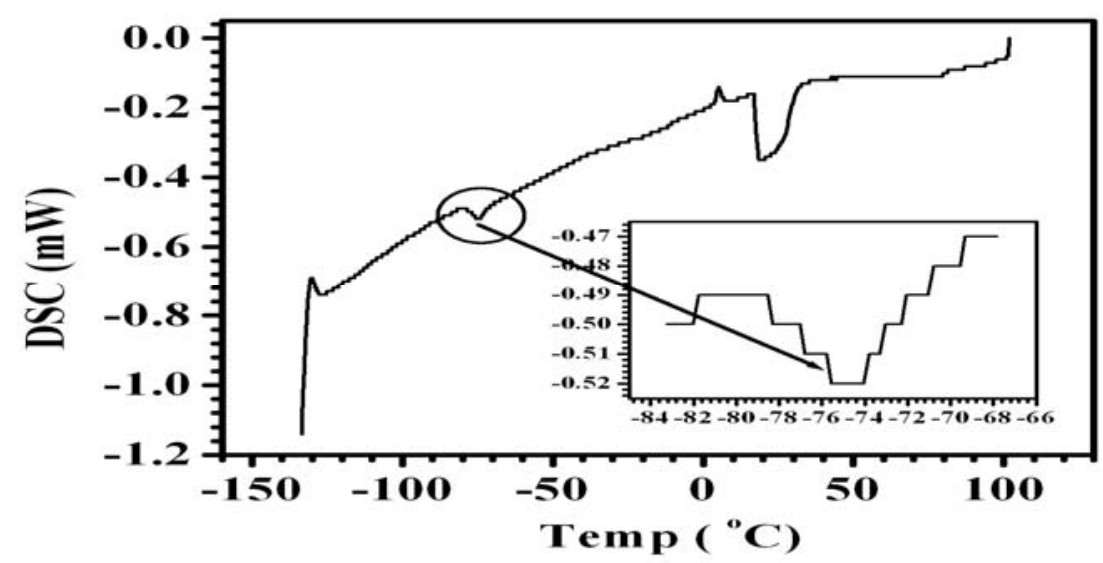

Fig. (6): DSC scans of natural rubber.

\section{6. $X$ ray diffraction}

The XRD data reveal the formation of amorphous phase of the prepared rubber samples at low angles $\left(10-35^{\circ}\right)$ Fig (7). The formed humps are broadening with the increase of temperature in the range of $\left(-30-60 \mathrm{C}^{\circ}\right)$. In an intermediate region $\left(42-45^{\circ}\right)$, a set of crystalline peaks are observed with the temperature range $\left(-30-60 \mathrm{C}^{\circ}\right)$. A new sharp observed peak was depicted at $\left(2 \theta=50.5^{\circ}\right)$ with the same position for all samples. Finally, a weak crystalline peak was revealed at $\left(2 \theta=74^{\circ}\right)$ for all the investigated samples. One can conclude that in agreement with (PAL) results, and the thermal expansion coefficient measurements for free volume, XRD measurements as a function of temperature detected the variation of the mobile domains. Whereas the temperature increases, the peak height of the crystalline decreases. The broadening which was indicated to amorphous domain increases which means that the free volume increases with temperature.

\subsection{Tensile Deformation}

After stretching the sample to (300\%), the positron annihilation measurements at room temperature during 1200 minutes did not show a steep change in the lifetime (Fig 8). This is may be because the measurements was constant at room temperature and below $T_{M}$ which shows that the sample crystallinity is still stable. Tensile deformation of the rubber sample at room temperature did not show any effect on the positron annihilation measurements, after stretching the sample to $300 \%$. 


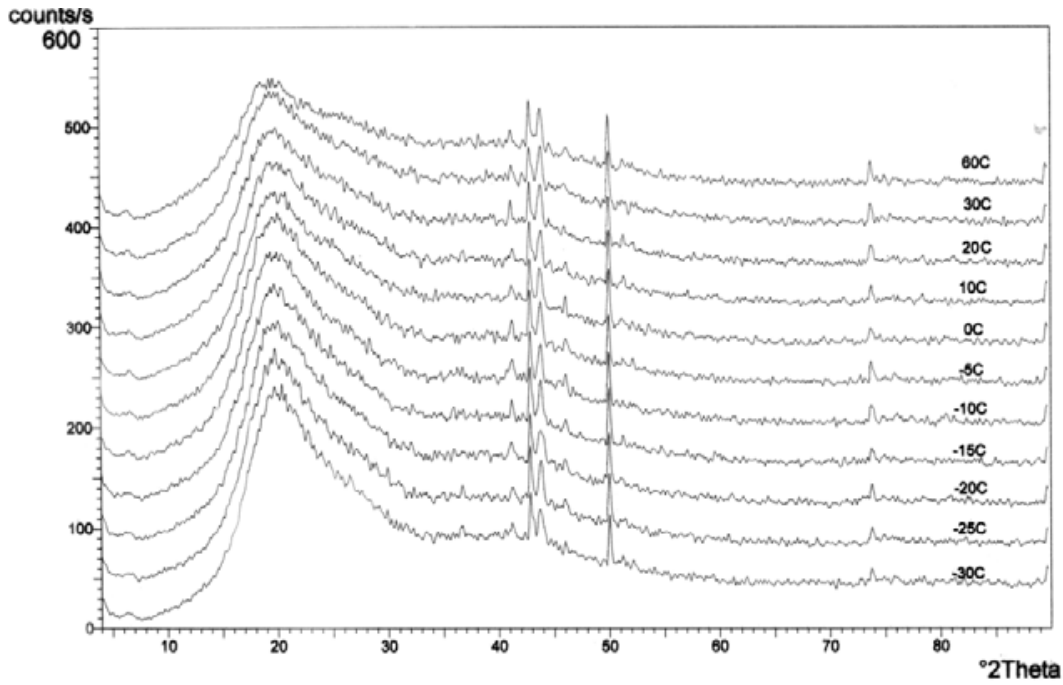

Fig. (7): XRD of natural rubber.

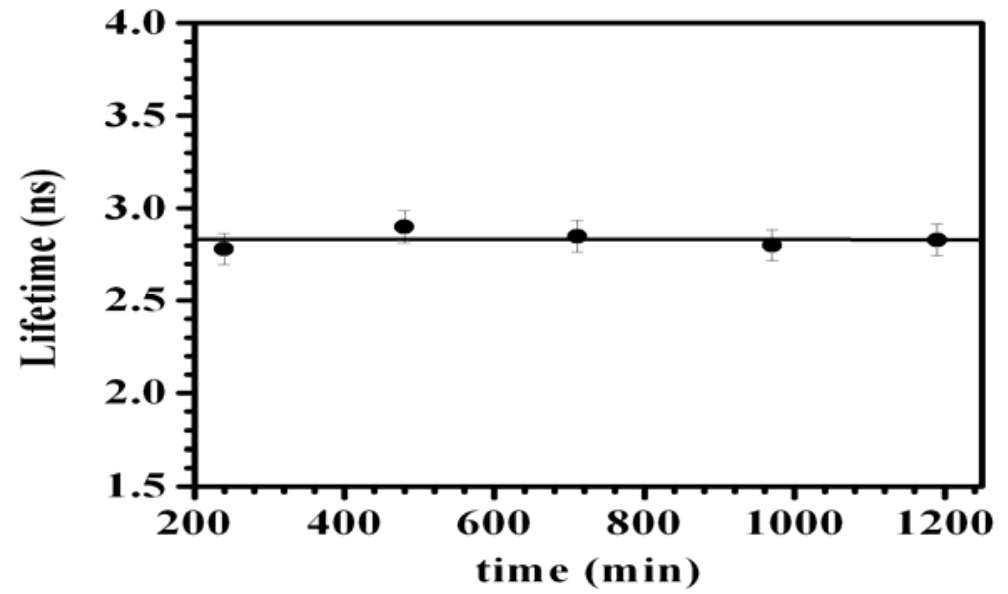

Fig. (8): Tensile deformation of natural rubber.

\section{Conclusion}

1. The positron lifetime spectra in natural rubber show four components, the small two components $\left(\tau_{2}=0.35-0.55 \mathrm{~ns}\right)$ and $\left(\tau_{3}=0.3-0.55 \mathrm{~ns}\right)$ are attributed to free positron annihilation in the interstitials of the matrix and at interface. Whereas the large component $\left(\tau_{4}=1.5-3.5 \mathrm{~ns}\right)$ is due to o-Ps annihilation in free volumes.

2. Ortho-positronium (o-Ps) annihilation is able to probe the variation of free volume properties with temperature in amorphous domains with size ranging from $42 \mathrm{~A}^{03}$ to $252 \mathrm{~A}^{03}$ in the temperature range from the glass temperature to the melting temperature. 
3. The expansion coefficient of free volume is found to be more than an order of magnitude higher than the volume expansion coefficient, indicating strong evidence of Ps trapping in free volume sites in amorphous domains.

4. Above $T_{g}$, the temperature variation of free volume indicates the presence of an intermediate transition point before the melting point which can be attributed to a less stable crystalline phase.

5. In agreement with DSC and XRD measurements, PAL gives the same temperatures for $T_{g}$ and $T_{m}$ and the nano free volume variation with temperatures.

\section{References:}

1. E.E. Abdel - hady, A. Abo Hashem, A.M.A. Elsayed, M. Mohsen, A.A. Ghani, Poly. Degra. stab., 41, 65 (1993).

2. F. H. Hsu, P. K. Tseng, S. Y. Chuang, Y.L. Chong, Chinese J. Phys. 16, 29 (1978).

3. N. Mostafa, M. Mohsen, Y.C. Jean, H. A. Ismail, Trans Tech Publications. Materials Science Forum., 255, 372 (1997).

4. M. Mohsen, A. Ismail, H.A. Ismail, A. Hassan, M. Hemdan, Rad. Phys. chem. (2004)

5. A. Sharaf, L. Johannes, W. Haskell, Beckham School of Polymer, Textile and Fiber Engineering, Georgia Institute of Technology, Atlanta, GA, 30332 (2004).

6. Marzocca, S. Cerveny, W. Salgueiro, A. Somoza, and L. Gonzalez. Phys. Rev., E. 65, 021801 (2002)

7. E. Gomaa, E. Hassan, M. Mohsen, J. of Poly. Sci. B: Poly. Phys., 47, 227 (2009).

8. J. Kansy, Nucl. Instrum., Method Phys. Res., A374, 235 (1996).

9. J. Liu, Q. Deng, Y. C. Jean, Macromolecules, 26, 7149 (1993).

10. M. B. Ashalatha, P. M. Sathyanarayana, G. Shariff, M. C. Thimmegowada, R. Ramani C. Ranganathaiah, Appl. Phys., A76, 1 (2003).

11. Y. C. Jean, Microchem. J., 42, 72 (1990).

12. S. J. J. Tao, J. Chem. Phys., 56, 5499 (1972).

13. M. Eldrup, D. Lightbody, J. N. Sherwood., Chem. Phys., 63, 51 (1981).

14. H. Nakanishi, S. J. Wang, Y. C. Jean, Positron Annihilation Studies of Fluids World Scientific Publication, Singapore, (1988).

15. O. E. Mogensen, Positron Annihilation in Chemistry (Springer, Berlin, 1995).

16. G. Dlubek, E. M. Hassan, R. Krause-Rehberg, J. Pionteck, Phys. Rev., E73, 031803 (2006).

17. Rubber Seals for Fluid and Hydraulic Systems, William Andrew, (2009).

18. T. Hirade, T. Oka Conference on Positron Annihilation (ICPA-16) IOP Publishing, J. of Phys.: Conference Series, 443, 012060 (2013). 